Яковлева Т. А., Чупров Р. Н.

T. A. Yakovleva, R. N. Chuprov

РИСКИ В ИНВЕСТИЦИОННОЙ ДЕЯТЕЛЬНОСТИ И УПРАВЛЕНИЕ ИМИ

\title{
RISKS IN INVESTMENT AND MANAGEMENT
}

Яковлева Татьяна Анатольевна - кандидат экономических наук, профессор кафедры «Экономика, финансы и бухгалтерский учет» Комсомольского-на-Амуре государственного технического университета (Россия, Комсомольск-на-Амуре). E-mail: kaf_et@knastu.ru.

Tatiana A. Ykovleva - PhD in Economics, Professor, Head of the Economics, Finance and accounting Department, Komsomolsk-on-Amur state technical university (Russia, Komsomolsk-on-Amur). E-mail: kaf_et@knastu.ru.

Чупров Роман Николаевич - магистрант кафедры «Экономика, финансы и бухгалтерский учет» Комсомольского-на-Амуре государственного технического университета (Россия, Комсомольск-на-Амуре). E-mail: Romancho_Chuprov@mail.ru.

Mr. Roman N. Chuprov - master's degree student, the Economics, Finance and accounting Department, Komsomolsk-on-Amur State Technical University (Russia, Komsomolsk-on-Amur). E-mail: Romancho_Chuprov@mail.ru.

Аннотация. В статье рассматриваются особенности инвестиционных рисков и причины их возникновения, а также приводится подробная классификация инвестиционных рисков. Далее авторы раскрывают сущность и содержание процесса управления инвестиционными рисками, представив материал для наглядности в виде схемы. В заключение статьи обосновывается использование системы специализированных институтов как способом исключения базового, или первичного инвестиционного риска.

Summary. The article discusses the features of investment risks and their causes, as well as provides a detailed classification of investment risks. The authors reveal the essence and content of the investment process, risk management, providing material for presentation in the form of a diagram. In conclusion, the article explains the use of the system of specialized institutions as a way to exclude the basic, or primary investment risk.

Ключевые слова: инвестиционная деятельность, экономическая неопределенность, риск, управление инвестиционными рисками, базовый риск.

Key words: investment, economic uncertainty, risk, management of investment risk, basic risk.

УДК 330.131.7:336.714

В широком смысле под инвестиционной деятельностью понимают комплекс действий, связанных с вложением и возвращением с прибылью финансовых ресурсов. Куплю-продажу долгосрочных активов и других объектов инвестировании, которые не являются денежным эквивалентом, принято считать инвестиционной деятельностью в узком смысле.

Можно выделить три основные цели инвестирования со стороны любого хозяйствующего субъекта, будь это физическое лицо, частная корпорация или государственная структура:

1) обеспечение прибыли от инвестиций;

2) преобразование финансовых сбережений в ценные бумаги;

3 установление контроля над деятельностью объекта инвестирования.

Приоритет одной из названных целей предопределяет выбор инвестиций определенного вида, большое количество разновидностей которых присутствует в современной рыночной экономике. Так, по объектам вложений различают прямые и портфельные инвестиции, по периоду инвестирования - краткосрочные и долгосрочные инвестиции, по форме собственности ресурсов инвестирования - государственные, частные, иностранные и совместные, по степени риска - рисковые и безрисковые. 
При этом любая инвестиционная деятельность связана с высоким уровнем неопределенности и риска, абсолютно безрисковых инвестиций не существует, даже если их возврат гарантируется государством.

Под неопределенностью понимается состояние неоднозначности развития определенных событий в будущем, незнание и невозможность точного предсказания основных величин и показателей развития объекта инвестирования, неполнота или неточность информации об условиях реализации инвестиционной деятельности, в том числе связанных с ними затратах и результатах. Неопределенность предполагает наличие нестабильности, при которой результаты действий не обусловлены, а степень возможного влияния этих факторов на результаты неизвестна.

Условия нестабильности являются дестабилизирующими по отношению к инвестиционной деятельности. Негативные проявления нестабильности заключаются в следующем:

- потеря устойчивости объекта инвестиционной деятельности, соответственно ухудшение количественных значений показателей, его характеризующих;

- изменение структуры и качественного состава объекта инвестиционной деятельности;

- ухудшение степени управляемости объектом инвестиционной деятельности.

Однако нужно отметить, что нестабильность для субъекта инвестиционной деятельности, помимо негативных тенденций и рисковых ситуаций создает возможности для новых уникальных событий, которые, в свою очередь, могут расширить спектр возможных инвестиционных решений. Признание нестабильности, как не парадоксально на первый взгляд, может помочь снизить инвестиционные риски.

Риском инвестиционной деятельности принято считать потенциальную, численно измеримую возможность неблагоприятных ситуаций и связанных с ними последствий в виде потерь, ущерба, убытков по сравнению с вариантом, который рассчитан при оптимальном использовании инвестиционных ресурсов, или появления дополнительных расходов в процессе инвестирования.

Инвестиционные риски возникают в связи с возможным несоответствием условий, которые учитываются при обосновании инвестиционного проекта, и фактическими условиями его реализации. Причины, по которым возникают отклонения, могут носить объективный или субъективный характер. К первой группе относятся поведение конкурентов, колебания конъюнктуры рынка, изменение хозяйственного законодательства, некомпетентные действия государственных органов власти и управления и т.п. Кроме того, точность расчетов при разработке проектов зависит от полноты информации по прогнозированию ситуации на длительный срок. Все эти проблемы связаны с существованием экономической неопределенности, уровень которой повышается в кризисные периоды.

Инвестиционные риски могут возникнуть также вследствие некомпетентности участников инвестиционной деятельности, в том числе самих инвесторов.

Разнообразие инвестиционных рисков и желание осознанного воздействия на них вызвали необходимость классификации инвестиционных рисков. С одной стороны, классификация последних строится на тех же принципах, что и для любых рисков. С другой стороны, особенности инвестиционной деятельности приводят к специфической классификации инвестиционных рисков.

Среди рисков, связанных с инвестиционной деятельностью, можно назвать следующие их разновидности:

- риски государственного регулирования: риски, связанные с изменением условий финансово-хозяйственной деятельности, изменением законодательства и риски национализации;

- политические риски: риски изменения социально-экономической стратегии развития, риски международных событий;

- социальные риски: риски качества рабочей силы, риски забастовок;

- природные и экологические риски: риски природных и техногенных катастроф, геологические риски;

- отраслевые риски: риски развития отрасли, риски конкурентоспособности производимой в отрасли продукции; 
Яковлева Т. А., Чупров Р. Н.

РИСКИ В ИНВЕСТИЦИОННОЙ ДЕЯТЕЛЬНОСТИ И УПРАВЛЕНИЕ ИМИ

- финансовые риски: риски покупательной способности денег (риски инфляции, валютные риски, риски обесценения ценных бумаг, банковские риски) и риски платежеспособности (риски ликвидности, кредитные, процентные риски, риски неплатежей);

- противоправные риски: риски террористических актов, риски внесудебного решения хозяйственных споров, мошенничества, имущественные риски;

- управленческие риски: риски проектирования, селективные, квалификационные риски;

- маркетинговые риски: риски недостаточного изучения сегмента рынка, риски неправильного выбора направлений сбыта;

- конкурентные риски: риски неконкурентоспособности продукции, товаров или услуг;

- производственные риски: риски нарушения условий поставок, невыполнения работ, строительно-монтажные, транспортные риски, риски ответственности, риски нанесения ущерба жизни и здоровью, имущественные риски;

- правовые или юридические риски: риски неправильного оформления документации, патентные, лицензионные риски, риски судебных споров.

Как было сказано выше, подробная классификация инвестиционных рисков призвана способствовать повышению эффективности управления ими с целью обеспечения успешной инвестиционного деятельности в условиях неопределенности.

Управление инвестиционными рисками можно представить как поэтапный процесс, целью которого является возмещение ущерба для субъекта хозяйствования, обеспечение устойчивой способности его препятствовать неблагоприятным ситуациям.

В процессе управления инвестиционными рисками обычно выделяют несколько последовательных действий или этапов (см. рис. 1):

1) Анализ риска - начальный этап, цель которого получение необходимой информации о структуре, свойствах объекта и существующих рисках, а также выполнение качественного анализа рисков. Собранной информации должно хватить для принятия адекватные решения на последующих этапах.

2) Этап количественного подхода, который опирается на информацию, полученную в ходе качественного анализа, и предполагает численное определение инвестиционного риска и рисков в целом. На данном этапе формируются значения вероятности наступления рисковых событий и их последствий, производится количественная оценка степени (уровня) риска, определяется допустимый в данной конкретной обстановке уровень риска.

Оценивая риск, который инвестор в состоянии принять, нужно исходить из специфики и важности инвестиционного проекта, из наличия необходимых ресурсов для его реализации и возможностей финансирования вероятных последствий риска. Степень допустимого риска определяется с учетом таких параметров, как размер и надежность инвестиций, запланированного уровня их рентабельности и других показателей, важных для инвестора.

3) Этап выбора методов снижения рисков. Данный этап предназначен для формирования политики направленной на борьбу с риском и неопределенностью.

Сегодня наиболее часто используемыми являются следующие методы снижения инвестиционных рисков:

- предотвращение риска;

- нормирование риска;

- распределение риска между участниками проекта;

- снижение степени риска;

- страхование риска.

4) Этап использования выбранного метода управления.

5) Этап отслеживания результатов и совершенствование системы управления риском. На данном этапе происходит обновление и пополнение информации о рисках, т.к. появившиеся новые данные позволяют принимать адекватные и своевременные решения. На этой основе осуществляется оценка эффективности проведенных мероприятий. 


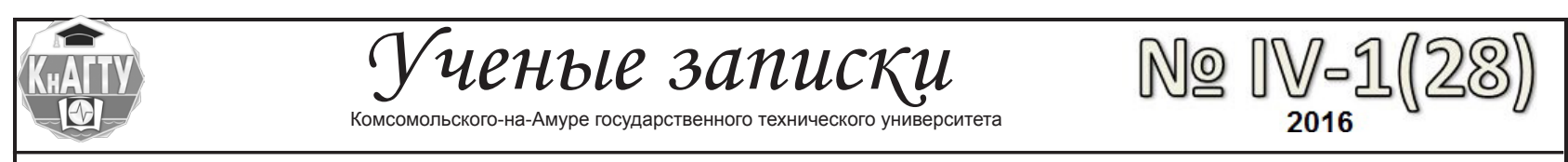

Если всех принятых мер недостаточно, то, возможно, следует отказаться от инвестирования, чтобы избежать риска.

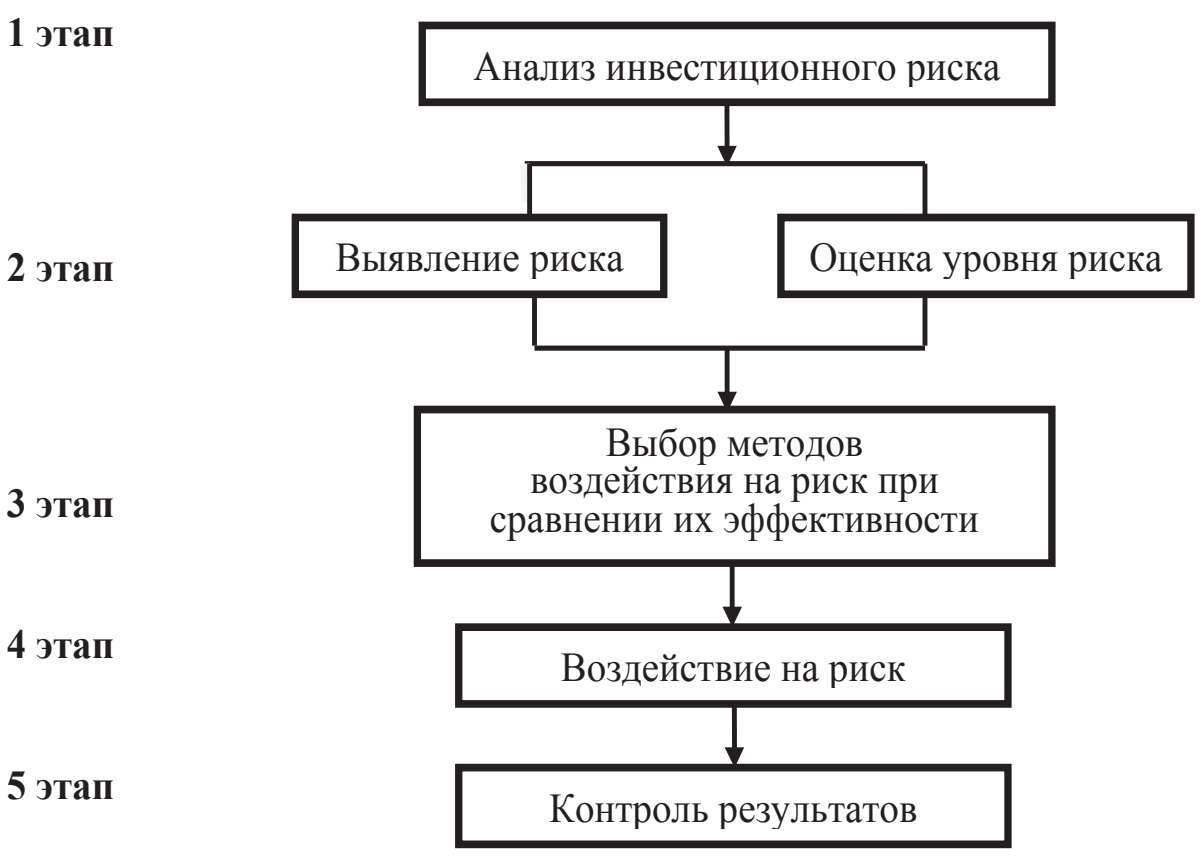

Рис. 1. Этапы управления инвестиционным риском

Рассмотренные этапы необязательно внедрять последовательно. Соответствующие мероприятия могут осуществляться параллельно, возможен возврат к предыдущим этапам и т.д.

Для инвестора работа по управлению рисками никогда не заканчивается, т.к. в ходе инвестиционной деятельности появляются новые риски. Задача инвестора состоит в выявлении этих рисков и определения подверженности потерям от риска.

В заключение следует отметить, что эффективность внедрения всех процедур управления рисками в 10 - 20 раз превышает и оправдывает затраты на разработку и реализацию всех мероприятий политики управления инвестиционными рисками. Разработка и внедрение элементов и процедур системы управления инвестиционными рисками позволяет исключить несвоевременное реагирование на рисковые ситуации на этапах планирования и реализации проекта, добиться уменьшения отклонений фактических показателей эффективности от запланированных при проектировании параметров, уменьшить уровень неопределенности в ходе реализации проекта, и, как следствие, дать гарантии выполнения поставленных целей инвестиционной деятельности путем уменьшения уровня риска минимум на $50 \%$ [3].

\section{ЛИТЕРАТУРА}

1. Москвин, В. А. Управление рисками при реализации инвестиционных проектов / В. А. Москвин. - М.: Финансы и статистика, 2004. - 352 с.

2. Ример, М. И. Экономическая оценка инвестиций / М. И. Ример, А. Д. Касатов, Н. Н. Матиенко; под общ. ред. М. И. Римера. - СПб.: Питер, 2005. - 480 с.

3. Шамин, Д. В. Управление рисками инвестиционного проекта «Деловой мир», 23 августа 2011 [Электронный ресурс]. - Режим доступа: https://delovoymir.biz/2011/08/23/upravlenie-riskami-investicionnogoproekta.html.

4. Инвестиции - хорошо или плохо? Общая информация об инвестициях [Электронный ресурс]. - Режим доступа: http://business.rin.ru/cgi-bin/search.pl?action=view\&num=342490\&razdel=0\&w=0. 